\title{
As imagens ficcionais no ensino de conceitos científicos ${ }^{3}$
}

\author{
Las imágenes de ficción en la enseñanza de los conceptos científicos \\ Ivan Carlos Pereira Gomes
${ }^{4}$
Wagner Wilson Furtado ${ }^{5}$
Agustina Rosa Echeverría $^{6}$
}

\section{RESUMO}

O trabalho apresentado é um recorte das análises desenvolvidas na dissertação de mestrado de GOMES (2013) e objetivou compreender como uma produção audiovisual, a partir de um relato histórico ficcional de um acidente radiológico, pode influenciar na compreensão de conceitos científicos. Ou seja, a partir de representações visuais ficcionais buscamos analisar a aprendizagem e a elaboração conceitual de conceitos próprios da ciência na sala de aula. A pesquisa se desenvolveu em uma turma de primeira série do ensino médio de uma escola particular da cidade de Goiânia. Tendo como referência autores da perspectiva sociocultural, em especial James Wertch e sua teoria da ação mediada, foi analisado o extrato de uma das aulas que integrou uma sequência didática cuja temática era a radioatividade. Inferimos que o filme amplia o contexto da discussão, porém limita quando o estudo passa a ser os conceitos científicos lá envolvidos. A produção audiovisual empregada não possuía objetivo pedagógico e pode-se argumentar que ela não tinha o objetivo de ensinar conceitos da ciência, mas as transformações da ação mediada poderiam permitir essa discussão. Destacamos o importante papel do professor, ao contribuir para alteração qualitativa na ação e ao auxiliar na aprendizagem de conceitos científicos pelos alunos durante as discussões na sala de aula.

Palavras-chave: Ferramenta cultural. Produção audiovisual. Elaboração conceitual. Radioatividade

\section{RESUMEN}

El artículo presentado és um resumen de las análisis dessarolladas en la pesquisa de mestrado de Gomes (2013) y tuvo como objetivo comprender como una producción audiovisual, a partir de un relato histórico de ficción de un accidente radiológico, puede influir en la comprensión de los conceptos científicos. Es decir, a partir de las representaciones visuales de ficción intentamos analizar el aprendizaje y el desarrollo conceptual de los propios conceptos de la ciencia en el aula. La investigación se desarrolló en una clase de primer grado de educación secundaria en una escuela privada en la ciudad de Goiânia. Tenemos como referencia estudiosos de la perspectiva sociocultural, especialmente James Wertch y su teoría de la acción mediada, se analizó el extracto de una clase que integra una secuencia de instrucción cuyo tema era la radioactividad. La producción audiovisual no tenía objetivo pedagógico y se puede argumentar que no estaba destinada a enseñar conceptos de la ciencia, pero las transformaciones de la acción mediada podrían permitir esta discusión. Hacemos destaque para la importancia del papel del maestro, por contribuir al cambio cualitativo de la acción y por ayudar en el aprendizaje de conceptos científicos por los estudiantes durante los debates en el aula.

Palabras clave: Herramienta cultural. Producción audiovisual. Elaboración conceptual. Radioactividad

\footnotetext{
3 Trabalho apresentado no dia 18 de outubro de 2013, no Grupo de Trabalho 2 - Representações visuais e as fronteiras da prática científica.

${ }^{4}$ Licenciado em Física e mestre em Educação em Ciências e Matemática (PMECM) pela Universidade Federal de Goiás (UFG). Investiga na área de Educação em Ciências com ênfase na perspectiva sócio-histórica e nos estudos de autores como Mikhail Bakhtin e James Wertsch. Atualmente é Técnico em Assuntos Educacionais na Universidade de Brasília (UnB). E-mail: gomesicp@gmail.com

5 Bacharel e licenciado em Física pela Universidade Federal de Goiás (UFG), mestre em Física pela Universidade de São Paulo (USP) e doutor em Física pela Universidade de São Paulo (USP). É professor associado da Universidade Federal de Goiás (UFG), atuando no Instituto de Física e no Programa de Mestrado em Educação em Ciências e Matemática (PMECM) da UFG. Atualmente, a principal área de atuação é a do Ensino de Física nos seguintes temas: Avaliação da Aprendizagem, Ensino e Aprendizagem, Teorias e Técnicas Educacionais e Ensino a Distância. E-mail: wwfurtado@gmail.com

${ }^{6}$ Licenciada, bacharel e mestre em Química, doutora em Educação pela Universidade Estadual de Campinas (UNICAMP). É professora associada da Universidade Federal de Goiás (UFG) atuando no Instituto de Química, no Mestrado em Educação em Ciências e Matemática (PMECM) e no Doutorado em Ciências Ambientais dessa universidade. Coordena o Núcleo de Pesquisa em Ensino de Ciências - NUPEC, da UFG e é lider do Grupo de Pesquisa em Educação Ambiental registrado no CNPq. Atualmente é coordenadora do Mestrado em Educação em Ciências e Matemática da UFG. E-mail: agustina@brturbo.com.br
} 


\section{INTRODUÇÃO}

O processo de institucionalização do ensino de Física no Brasil é relativamente novo. A introdução na educação formal começou timidamente no Colégio Pedro II, no segundo quarto do século XIX, e somente em 1934 o primeiro curso de graduação foi instituído no país. Este curso foi fundado na Universidade de São Paulo e formou dezenas de bacharéis e licenciados antes da introdução da disciplina de Física nos currículos da educação básica, em 1950. Obviamente esta introdução, não foi uma decisão ao acaso, pois ocorria no país um forte processo de industrialização e as ciências naturais, após a segunda guerra, passaram a ser vistas com outros olhos. Neste início, o ensino de Física possuía como característica um caráter conteudista e matematizado, chegando ao extremo de alguns vestibulares eliminarem totalmente questões conceituais qualitativas (CHIQUETTO; KAPRAS, 2012). Apesar das discussões na área, poucas alterações significativas ocorreram e o ensino continuou voltado, principalmente, para transmissão de conteúdos em aulas expositivas e para a resolução de problemas (ROSA; ROSA, 2005).

Esta postura simplista se reflete na dificuldade de aprendizagem de diversos conceitos e a causa deste problema, apontada por vários professores, é o insuficiente embasamento matemático dos alunos. A matemática tem importância fundamental, mas é preciso compreender também que a aprendizagem de conceitos científicos pode acontecer de forma dialógica e contextualizada, valorizando as vozes dos alunos, dos professores e as diversas perspectivas apresentadas nos diferentes meios de comunicação.

Apresentaremos neste trabalho um recorte das análises realizadas na dissertação de GOMES (2013), onde, a partir do desenvolvimento de uma sequencia didática para turmas da primeira série do ensino médio, alunos, empregando uma produção audiovisual, discutiram e elaboraram conceitos científicos relacionados ao tema radioatividade. Portanto, invertemos a lógica do livro didático, ou seja, a partir de imagens ficcionais, produzidas não necessariamente para serem utilizadas na escola, buscamos ensinar ciências. Serão apresentados no decorrer do trabalho, nossos referenciais teóricos e como, a partir deles, a análise foi realizada. 


\section{REFERENCIAL TEÓRICO}

As discussões deste trabalho serão fundamentadas, principalmente, na teoria da ação mediada de James Wertsch (1999). Ao desenvolver a teoria o autor entende que a ação humana é mediada e concentra a análise na relação entre o agente, aquele que realiza a ação, e a ferramenta cultural, mediadora da ação. Esta característica estabelece importantes conexões com as ideias dos teóricos como Vigotski e Bakhtin, aquele com ênfase na mediação dos signos na atividade humana e este com ênfase no enunciado (WERTSCH, 1991).

A análise marxiana do trabalho tanto explica os modos de produção, cuja finalidade era esta, como também permite explicar a função mediadora que o trabalho estabelece entre os homens e a natureza e entre si mesmo. Entretanto, é somente com Vigotski que essa qualidade mediadora é ampliada, por meio da instrumentalidade semiótica (PINO, 2001). Na perspectiva vigotskiana, todas as nossas relações são necessariamente mediadas e em um "sentido amplo, a mediação é toda intervenção de um terceiro elemento que possibilita a interação entre os termos de uma relação" (PINO, 1991, p. 32). Vigotski estabelece que a atividade indireta acontece por meio de instrumentos físicos e instrumentos semióticos, ou simplesmente signos. Os signos desempenham papel semelhante ao uso de instrumentos físicos, porém aqueles orientados para o próprio indivíduo, enquanto estes para objetos externos. "O signo age como um instrumento da atividade psicológica de maneira análoga ao papel de um instrumento no trabalho" (VIGOTSKI, 2007, p. 52) e ambos são acessórios na atividade humana, possuindo em comum a função mediadora.

Assim, os homens desenvolveram formas muito próprias de se comunicar. Porém, para que a comunicação pudesse acontecer não bastaria colocar face a face dois indivíduos e esperar que os signos se constituíssem, foi essencial que existisse uma organização social para que um sistema simbólico sofisticado pudesse ser elaborado (BAKHTIN, 2009).

Bakhtin analisa a língua inserida em um processo contínuo de evolução que se realiza em um fluxo ininterrupto mediante interações sociais. Em síntese, o ouvinte e o falante se tornam participantes ativos no processo histórico de comunicação discursiva, constituídas por meio de atos de fala. O produto, não 
cristalizado, dos atos de fala são precisamente os enunciados escritos ou orais (BAKHTIN, 2009).

Diferentemente da gramática e do dicionário, o fenômeno de interação verbal, composto pelos enunciados, é a verdadeira substância da língua fluída e dinâmica. Ademais, cada campo de atividade humana se caracteriza por enunciados próprios daquele grupo e quando são relativamente estáveis, são denominados gêneros do discurso. Bakhtin (2003) trata dos gêneros discursivos primários (simples - comunicação diária) e dos gêneros discursivos secundários (complexos romance, drama, pesquisas científicas etc.).

Quando o enunciado é analisado em uma situação de comunicação discursiva, desvendamos uma série de palavras semilatentes de outros. Isto quer dizer que o enunciado está carregado por outras vozes, conceito bakhtiniano que não se reduz aos sinais vocais e auditivos. A noção de voz surge da aproximação entre os conceitos de enunciado e a caracterização dos sujeitos participantes da interação. A principal razão deste vínculo é que um enunciado só pode ser produzido a partir de um ponto de vista, ou seja, por uma voz específica (WERTSCH, 1991; GIORDAN, 2008).

\section{METODOLOGIA}

A análise apresentada neste trabalho é parte de uma pesquisa que foi realizada em uma turma da primeira série do ensino médio de uma escola particular da cidade de Goiânia. A intervenção aconteceu em treze aulas de cinquenta minutos que foram organizadas compondo uma sequência didática.

A sequência didática teve como referência os conceitos envolvidos com a radioatividade. A escolha do tema buscou fugir da saturação dos tópicos da mecânica clássica, ter pretensão interdisciplinar e apresentar de alguma forma relevância e implicações sociais. Um fato do outro lado do mundo nos auxiliou nesta escolha. No primeiro semestre de 2011, uma onda gigantesca - tsunami - atingiu a costa do Japão e provocou, além de milhares de mortes, a destruição de cidades e graves danos a usinas termonucleares, importante fonte de energia do país. Assim, 
as discussões relativas aos riscos dos tsunamis e terremotos estimularam debates que resgataram uma temática adormecida, especificamente, a radioatividade.

A sequência didática se estruturou em uma abordagem que iniciou com temas mais amplos e concretos, indo em direção ao específico e abstrato. Isto é, as primeiras aulas da sequência tiveram como tema central aspectos históricos dos estudos iniciais sobre a radioatividade e alguns acidentes radioativos e radiológicos ocorridos no mundo. A partir daí, caminhamos em direção ao abstrato, como discussões referentes à eletrosfera, aos raios-X, ao núcleo atômico e aos decaimentos nucleares.

$\mathrm{Na}$ intenção de aprofundarmos e ampliarmos o contexto das discussões, buscamos ferramentas culturais diferentes do livro didático tradicional. A escolha se pautou em ferramentas culturais que pudessem alterar a ação na sala de aula, ou seja, que estimulasse a elaboração de enunciados diante de diferentes vozes, significando os conceitos chave e ampliando a discussão científica. Em resumo, a seleção tinha como horizonte uma transformação qualitativa da ação. Por conseguinte, uma das ferramentas culturais escolhidas foi um vídeo de longa metragem nacional.

Para o estudo, foram feitos registros audiovisuais e os diálogos de todas as aulas foram transcritos. A metodologia de análise deste trabalho se aproxima do dispositivo analítico proposto no trabalho de Silva et al. (2012), onde o enunciado é identificado, o contexto extraverbal é descrito e, finalmente, os enunciados são analisados a partir da teoria da ação mediada e dos conceitos linguísticos bakhtinianos. Em nosso contexto, a última etapa focará na elaboração conceitual a partir de diferentes vozes, isto é, das imagens e encenações da produção audiovisual.

\section{ANÁLISE DOS DADOS}

A análise apresentada neste trabalho se concentra no episódio de ensino de uma das aulas da sequência didática. Todos os registros foram transcritos e organizados em unidades de análise, enfocando a significação dos conceitos científicos tratados em aula e as várias vozes que se entrelaçaram na dinâmica 
discursiva. Episódio de ensino é definido como um conjunto de enunciados que cria o contexto próprio para a emergência de significados (AMARAL; MORTIMER, 2006) e aqui compôs um quadro que contempla a identificação do participante, o seu enunciado, denominado turno, e o seu número correspondente. As transcrições foram caracterizadas por sua função: PR para professor regente e A, seguido de um número, para alunos.

\subsection{IDENTIFICAÇÃO DOS ENUNCIADOS}

O filme Césio 137 - o pesadelo de Goiânia é uma obra ficcional que retrata os acontecimentos que antecederam o acidente radiológico ocorrido em 1987 na capital goiana. Embora seja baseada em fatos reais e tenha exigido uma pesquisa história, a produção não possuía intencionalidade pedagógica, ou seja, ela não foi produzida, necessariamente, para a escola. A trajetória dos principais envolvidos na tragédia foi representada na obra.

\subsection{DESCRIÇÃO DO CONTEXTO EXTRAVERBAL}

A intervenção aconteceu em treze aulas que fizeram parte de uma sequência didática. Os conceitos científicos envolvidos na radioatividade foi tema central da sequência didática. Enquanto na primeira metade os conceitos concretos foram discutidos naturalmente, na segunda metade o professor empenhava-se em guiar e auxiliar na elaboração conceitual dos alunos. A intenção era a de distinguir, entre outros conceitos, 0 raio- $X$ da radioatividade, o último entendido aqui especificamente como a radioatividade nuclear. Essa discussão foi recorrente durante as aulas e o professor, ao identificar isso, fazia a distinção a partir da origem das radiações e de associações com alguns equipamentos médicos. Portanto, os enunciados que serão analisados estão inseridos neste contexto. 


\subsection{ANÁLISE DOS ENUNCIADOS}

Nos turnos a seguir a distinção entre raio-X e radioatividade é abordada a partir da ferramenta cultural filme. Nele, dois catadores de materiais recicláveis encontram uma máquina de radioterapia abandonada em um prédio. Eles desmontam o aparelho e levam para um ferro velho somente o invólucro de chumbo, que continha o material radioativo.

\begin{tabular}{|l|l|}
\hline Turno & Transcrição das falas \\
\hline 14 & PR: por que você acha que não era aparelho de raio-X? \\
\hline 15 & $\begin{array}{l}\text { A3: porque você falou agorinha que tinha que ligar na tomada pra ser de raio-X... } \\
\text { ((interrompida por um aluno)) }\end{array}$ \\
\hline 16 & A1: mas aquilo era só uma peça! \\
\hline 17 & A2: do aparelho de raio-X! \\
\hline 18 & PR: era uma peça, mas era uma peça de um aparelho de raio-X? \\
\hline 19 & A4: eu acho que não era. \\
\hline 20 & A3: eu também acho que não era. \\
\hline 21 & $\begin{array}{l}\text { PR: ((pede silêncio e aponta para um aluno que queria falar)) Fala aí primeiro H. } \\
\text { ((nome do aluno)) }\end{array}$ \\
\hline 22 & A5: que era um aparelho de quimioterapia. \\
\hline 23 & $\begin{array}{l}\text { PR: devia ser uma máquina de quimioterapia?... Olha o que o C. ((nome do aluno)) } \\
\text { fala. Fala aí C.! }\end{array}$ \\
\hline 24 & $\begin{array}{l}\text { A6: parece que a clínica era pra tratamento do câncer e pro câncer não usa raio-X } \\
\text { como tratamento. }\end{array}$ \\
\hline 25 & A2: mas não era só contra o câncer! \\
\hline 26 & A(-): ((inaudível)) \\
\hline 27 & PR: meninos eu não tô escutando. ((chama a atenção da turma)) \\
\hline 28 & $\begin{array}{l}\text { A7: que aquele chumbinho que tava dentro do negócio, aí a gente não precisava ligar } \\
\text { na tomada pra ele funcionar. A partir do momento que mexesse nele ele já tava } \\
\text { emitindo, por isso eu acho que era uma máquina de raio-X. }\end{array}$ \\
\hline 29 & PR: você acha que não era? \\
\hline 30 & A7: acho que era uma máquina de raio-X! \\
\hline 31 & PR: calma aí. Mas você acabou de falar que... ((é interrompido pela aluna)) \\
\hline 32 & $\begin{array}{l}\text { A7: ((incompreensível)) aquele aparelho não precisava carregar na tomada pra ela } \\
\text { emitir a radiação que tava lá dentro. }\end{array}$ \\
\hline 33 & PR: isso. \\
\hline 34 & $\begin{array}{l}\text { A7: a partir do momento que tirasse então e abrisse lá aquele chumbinho ela podia } \\
\text { emitir radiação pra qualquer parte. }\end{array}$ \\
\hline Quana
\end{tabular}

Quadro 1 - Episódio de ensino ocorrido durante a aula 10.

O professor estimula a discussão de temas relacionados aos conceitos científicos envolvidos no filme exibido. Mesmo que recorrente, a diferença entre raio$X$ e radioatividade não estava completamente clara entre os alunos. Aqui a crítica de Bakhtin (2009) ao modelo falante-ouvinte faz todo sentido. Se o processo de comunicação é linear e a mensagem é clara, então toda a comunicação deveria ser garantida e a polissemia, entre os termos, eliminada. Assumindo a complexidade e a 
não linearidade do processo de comunicação, o professor incentiva o diálogo ao relacionar os conceitos envolvidos em aplicações tecnológicas na medicina com as outras ferramentas culturais empregadas em sala.

Alguns alunos identificam a trajetória dos catadores, mesmo sem ainda precisar que tipo de máquina foi violada. O entendimento do curso dos acontecimentos é reconstruído, quer dizer, os signos imagéticos são esclarecidos por outros diferentes signos (BAKHTIN, 2009). O processo de significação dos conceitos científicos também passa por esse estágio, pois se os teores das discussões não fizerem parte do horizonte conceitual do estudante, nada adianta utilizar distintas metodologias e ferramentas culturais.

Posto que os alunos A2, A4 e A5, não conseguiram justificar adequadamente suas escolhas, as réplicas são elaboradas a partir de enunciados anteriores ou de algum tipo de elaboração conceitual feita por eles. Há a aluna A7, que sugere o tipo da máquina e justifica bem sua resposta. Porém, existe um problema: a explicação está correta, mas o aparelho citado está errado. Ou a aluna se confunde momentaneamente, ou ela não compreendeu a diferença entre os dois aparelhos e suas respectivas emissões radioativas.

Em aulas anteriores, o professor enfatiza a necessidade de fornecer energia para a máquina de raio- $X$, ligando-a na tomada. Outras máquinas, de quimioterapia, por exemplo, tem como princípio o decaimento natural do elemento químico armazenado. O enunciado "não precisa carregar na tomada", turno 32, retoma a voz do professor, no entanto, ele fica solto, não se relacionando com nenhuma ferramenta cultural ou elaboração conceitual, aliás, existe uma grande confusão nas elaborações da aluna A7. A ferramenta cultural filme amplia o contexto da discussão para aqueles que não conheciam que tipo de acidente radiológico aconteceu em Goiânia, porém, limita quando o estudo passa a ser os conceitos científicos lá envolvidos.

\section{CONSIDERAÇÕES FINAIS}

Há indícios nas análises que o emprego de ferramentas culturais diferentes do livro didático, na sala de aula, pode provocar alguns limites nas elaborações de 
conceitos científicos. Embora a ferramenta cultural filme da sequência didática não tenha objetivo de ensinar ciências, as transformações da ação mediada poderiam permitir que essa discussão ocorresse. Destacamos, então, o alargamento do contexto da discussão científica no uso de diferentes ferramentas culturais e o papel fundamental do professor, ao dialogar e negociar significados com os alunos.

Agradecemos à CAPES pelo apoio financeiro.

\section{REFERÊNCIAS}

AMARAL, Edênia M. R.; MORTIMER, Eduardo F. Uma metodologia para análise da dinâmica entre zonas de um perfil conceitual no discurso da sala de aula. In: SANTOS, Flávia M. T.; GRECA, lleana M. A pesquisa em Ensino de Ciências no Brasil e suas metodologias. ljuí: Ed. Unijuí, 2006. p.239-296.

BAKHTIN, Mikhail. Estética da criação verbal. 4. ed. São Paulo: Martins Fontes, 2003.

BAKHTIN, Mikhail. (VOLOCHÍNOV). Marxismo e filosofia da linguagem. 13. ed. São Paulo: Hucitec, 2009.

CÉSIO 137 - o pesadelo de Goiânia. Direção e roteiro Roberto Pires. Brasil: Grupo Coplaven, 1990. 1 DVD remasterizado (115 min.): DVD, col., son. Port.

CHIQUETTO, Marcos J.; KRAPAS, Sonia. Examinando exames: análise dos vestibulares que nortearam o livro "Fundamentos da Física". Caderno Brasileiro de Ensino de Física, Florianópolis, v.29, n.1, p.33-51, abr. 2012.

GIORDAN, Marcelo. Computadores e linguagens nas aulas de ciências. ljuí: Editora UNIJUÍ, 2008.

GOMES, Ivan C. P. A mediação semiótica de instrumentos culturais na aprendizagem do conceito de radioatividade no Ensino Médio. 2013. 111 f. Dissertação (Mestrado em Educação em Ciências e Matemática), Universidade Federal de Goiás, Goiânia, 2013.

PINO, Angel. O conceito de mediação em Vygotsky e seu papel na explicação do psiquismo humano. In: GÓES, Maria Cecília; PINO, Angel (org.). Caderno Cedes 24 - Pensamento e linguagem: estudos na perspectiva da psicologia soviética. 1. ed. Campinas, SP: Papirus, 1991. p. 32-43. 
PINO, Angel. O biológico e o cultural nos processos cognitivos. In: MORTIMER, Eduardo F.; SMOLKA, Ana Luiza B. (org.). Linguagem, cultura e cognição: reflexões para o ensino e a sala de aula. Belo Horizonte: Autêntica, 2001. p.21-50.

SILVA, Jorge Luís A.; CAVALCANTI, Cláudio José de H; OSTERMANN, Fernanda. Uma análise bakhtiniana de textos didáticos de Física à luz dos pressupostos teóricos do movimento CTS. In: Encontro de Pesquisa em Ensino de Física, 2012. Maresias. Anais eletrônicos. Disponível em:

$<$ http://www.sbf1.sbfisica.org.br/eventos/epef/xiv/sys/resumos/T0109-1.pdf>. Acesso em: 10 jul. 2013.

ROSA, Cleci W.; ROSA, Álvaro B. Ensino de Física: objetivos e imposições no ensino médio. Revista Electrónica de Enseñanza de las Ciencias, v.4, n.1, 2005.

VIGOTSKI, L. S. A formação social da mente. 7. ed. São Paulo: Martins Fontes, 2007.

WERTSCH, James V. Voces de la mente - un enfoque sociocultural para el estudio de la Acción Mediada. Madri: Visor, 1991.

WERTSCH, James V. La mente en acción. 1. ed. Buenos Aires: Aique, 1999. 